\title{
Evolutionary history of Serpulaceae (Basidiomycota): molecular phylogeny, historical biogeography and evidence for a single transition of nutritional mode
}

\author{
Inger Skrede ${ }^{1 *}$, Ingeborg B Engh ${ }^{1}$, Manfred Binder ${ }^{2}$, Tor Carlsen ${ }^{1}$, Håvard Kauserud $^{1}$ and Mika Bendiksby ${ }^{3}$
}

\begin{abstract}
Background: The fungal genus Serpula (Serpulaceae, Boletales) comprises several saprotrophic (brown rot) taxa, including the aggressive house-infecting dry rot fungus Serpula lacrymans. Recent phylogenetic analyses have indicated that the ectomycorrhiza forming genera Austropaxillus and Gymnopaxillus cluster within Serpula. In this study we use DNA sequence data to investigate phylogenetic relationships, historical biogeography of, and nutritional mode transitions in Serpulaceae.

Results: Our results corroborate that the two ectomycorrhiza-forming genera, Austropaxillus and Gymnopaxillus, form a monophyletic group nested within the saprotrophic genus Serpula, and that the Serpula species S. lacrymans and S. himantioides constitute the sister group to the Austropaxillus-Gymnopaxillus clade. We found that both vicariance (Beringian) and long distance dispersal events are needed to explain the phylogeny and current distributions of taxa within Serpulaceae. Our results also show that the transition from brown rot to mycorrhiza has happened only once in a monophyletic Serpulaceae, probably between 50 and 22 million years before present.
\end{abstract}

Conclusions: This study supports the growing understanding that the same geographical barriers that limit plantand animal dispersal also limit the spread of fungi, as a combination of vicariance and long distance dispersal events are needed to explain the present patterns of distribution in Serpulaceae. Our results verify the transition from brown rot to ECM within Serpulaceae between 50 and 22 MyBP.

\section{Background}

Studying fungal distributions in an evolutionary context is relatively new, mainly due to the long-standing perception that fungi are more or less free from dispersal barriers, and that fungal distributions are primarily controlled by the distribution of hosts and substrata (see [1]). However, this notion of "cosmopolitan species" has recently been challenged by molecularly based studies [2-4]. Fungal distributional patterns can be complicated by the fact that cryptic species and polyphyly often are revealed in molecular based fungal studies. Thus, molecular phylogenetic approaches have proven important

\footnotetext{
* Correspondence: inger.skrede@bio.uio.no

'Microbial Evolution Research Group (MERG), Department of Biology,

University of Oslo, P.O. Box 1066 Blindern, N-0316 Oslo, Norway

Full list of author information is available at the end of the article
}

for the identification of unique lineages with restricted distributions [3]. Although it is obvious that hosts impose some restriction on the distribution of their parasite or symbiont (e.g. [5]), Taylor et al. [3] argue that very few (if any) organisms can be considered free of entanglement with other organisms. In fact, Parrent et al. [6] suggested that high levels of host specificity increase the effect of isolation-by-distance.

Vicariance versus long distance dispersal are two alternative explanations to widely disjunct distributions, and have been identified to operate in most groups of organisms $[7,8]$. It is becoming increasingly accepted that the same barriers to dispersal operate in fungi as in other groups of organisms [1,2]. Vicariance has given explanatory power for disjunct distributions in some extomycorrhizal fungi such as pacific boletes [9] and truffle-formin 
fungi in the Hysterangiales [10], while dispersal best explains the distribution of the wood-rot fungi Ganoderma [11].

Molecular dating makes it possible to relate organismal evolution to major ecological and geological events. The combination of fossils that correlate to divergence events in organismal phylogenies with increasingly realistic models of molecular evolution has increased the accuracy of molecular dating [12]. Reliable fossils are preferred for calibration of molecular clocks. However, dated geographic and ecological events as well as age estimates of symbiotic or parasitic partners have also been used [13-15], either in combination with fossil calibration or as the best available alternative when no reliably determined and correctly assigned fossils exist. Unfortunately, the fossil record of fungi is sparse [12], and several studies have attempted to date evolutionary splits of fungi using various calibration strategies (e.g. [15-20]). An additional complicating factor in molecular dating is between-lineage rate heterogeneity of molecular evolution, which has been extensively documented in fungi (see [12] and references therein). However, methods have been developed that account for rate heterogeneity by various sophisticated relaxed clock models (e.g. BEAST [21]).

In recent times, the fungal tree of life has been largely redrawn by molecular phylogenetics. This has in turn improved our understanding of how different nutritional modes have evolved [22-24]. The Agaricomycetes is a class in the fungal kingdom that contains most of the forest floor mushroom-forming fungi [25]. Currently saprotrophy (possibly white rot) is suggested to be the plesiomorphic state of the Agaricomycetes [26], while brown rot and ectomycorrhiza have evolved several times independently from the ancient white rot state. Ectomycorrhizal (ECM) fungi form mutualistic interactions between plant roots and fungal mycelia. The symbiosis provides the plant with important nutrients such as phosphorous and nitrogen, and the fungi receive photosynthetic products in return $[27,28]$. Mycorrhizal symbioses are ubiquitous in natural plant environments [29-31]. Saprotrophy by white rot decomposes lignocellulose and utilize all parts of the wood. Brown rot, on the other hand, only deforms the lignin to get access to the cellulose and hemicelluose, which are then efficiently depolymerized and absorbed by the fungus $[32,33]$.

Recent work shows that ECM is a nutritional mode that has evolved several times independently in both plants and fungi (both Basidiomycota and Ascomycota) $[28,34]$. Hibbett and Matheny [26] concluded that there have been many independent origins of ECM associations of Agaricomycetes with both Angiosperms (at least 8) and Gymnosperms (at least 6-8). The monophyletic basidiomycete order Boletales comprises various nutritional modes, including ECM, saprotrophy and parasitism $[35,36]$. Brown rot has been suggested as the plesiomorphic state for the Boletales [37].

The genus Serpula (Pers.) Gray in the Boletales consists of saprotrophic taxa that mainly degrade conifer substrates [37]. Serpula species produce annual, brownish, and resupinate fruitbodies (flat structures adhered to a woody or soil substrate with a morphological cariable sexual spore-producing surface; in the case of Serupla this spore producing surface is wrinkled or merulioid) $[38,39]$. Many Serpula species appear frequently on structural timbers in buildings, including $S$. himantioides $(\mathrm{Fr}$.) P. Karst., S. incrassata (Berk. \& M.A. Curtis) Donk and S. lacrymans (Wulfen) J. Schröt [40]. Serpula lacrymans is very aggressive in buildings and produces what is commonly known as dry rot (ref). The taxonomic circumscriptions of Serpula himantioides and S. lacrymans have varied through time: they are lumped as one based on morphology [41] or recognized as two separate species based on mating experiments [42]. The morphotaxon S. lacrymans includes two varieties. One of them (var. shastensis Harmsen) seems to have a natural distribution in the Cascade Range in western North America, while the other (var. lacrymans [Wulfen] J. Schröt.) has a natural distribution in northeast Asia from where it has spread to most continents and colonised buildings (see [43] and references therein). The morphotaxon S. himantioides includes multiple (at least five) cryptic species $[44,45]$, most of them with a primary affinity to southern South America and North America. Serpula incrassata seems to have a strictly North American distribution [41]. A less studied species, Serpula puverulenta (Fr.) Bondartsev, which also appears in houses, has at least a European and probably also a North American distribution $[46,47]$. Serpula similis (Berk. \& Broome) Ginns is known from tropical regions in Africa and southeast Asia, where it is sampled on bamboo and hardwoods $[48,49]$.

Molecular phylogenetic analyses have indicated that the ECM-forming genera Austropaxillus Bresinsky \& Jarosch and Gymnopaxillus E. Horak are nested within Serpula, and the family Serpulaceae Jarosch \& Bresinsky was described comprising these three genera [50]. Austropaxillus species have fruiting bodies with a stipe (stem) and pileus (cap), and a bear a gilled hymenophore (spore-producing surface). In contrast, Gymnopaxillus encompasses truffle-like hypogeous (under ground) fruit bodies [51]. Due to morphological and ecological similarities, these genera were earlier included in Paxillus Fr. [52]. Austropaxillus and Gymnopaxillus form ECM with roots of Nothofagus and Eucalyptus trees and are known only from the temperate Southern Hemisphere.

The aim of the present study was threefold. First, we wanted to further investigate phylogenetic relationships 
within Serpulaceae (previously described in $[37,52]$ ), in particular the relationship between the saprotrophic Serpula and the mycorrhiza-forming Austropaxillus and Gymnopaxillus. Secondly, we wanted to relate major Serpulaceae divergence events and ecological transitions to geologic and climatic conditions of the past. Finally, we wanted to reveal how many times the transition from brown rot to mycorrhizal symbiosis has occurred in Serpulaceae including reconstructing its ancestral biographical range within a historical geological context. We addressed these issues using a molecular phylogenetic approach, including Bayesian age estimation and various ancestral area analyses, on a multi-locus dataset.

\section{Methods}

\section{Taxon sampling}

We generated DNA sequence data from 30 accessions of five Serpula species and six accessions representing six species of Austropaxillus (Additional file 1: Specimens included in this study). In the phylogenetic analysis, we included an extensive set of outgroups from both the Boletales (41 accessions) and its sister group the Atheliales, the latter used for rooting purposes (Dataset1). For the purpose of dating, we reduced the boletalean outgroup to 24 accessions, expanded the athelialean outgroup to seven accessions, and included 1-24 accessions from each of nine additional fungal orders (Dataset2). Sequences not generated for the present study were taken from Binder et al. [53] and Jarosch and Bresinsky [50]. We used a total of 79 accessions for the phylogenetic analyses (Dataset1) and 109 accessions in the dating analysis (Dataset2). A separate phylogenetic analysis was performed on a reduced dataset of 39 accessions (Serpulaceae and a single outgroup taxon; Dataset3) to depict the phylogenetic position of Gymnopaxillus, for which only sequences of a single genetic region are available. All included accessions are listed in Additional file 1.

\section{DNA extraction, PCR amplification and DNA sequencing}

A small amount of fungal tissue was homogenized on a Mixer Mill (MM301, Retsch GmbH \& Co., Haan, Germany) before we extracted total DNA following the 2\% CTAB miniprep method described by Murray and Thompson [54] with minor modifications from Gardes and Bruns [55]. We dissolved the dried DNA pellet in $100 \mu \mathrm{L}$ milli-Q $\mathrm{H}_{2} \mathrm{O}$, and used further dilutions for the molecular work. We have deposited the DNA aliquots in the fungal DNA collection at the Institute of Biology, UoO, Norway.

Five nuclear DNA regions were amplified: the nuclear ribosomal large subunit (LSU) using the primers LROR/ LR5 [56], the nuclear ribosomal small subunit (SSU) using the primers PNS1/NS41 [57], the nuclear ribosomal 5.8S using the primers ITS5 and ITS4 [58], a fragment of the gene that encodes the second largest subunit of the RNA polymerase II ( $r p b 2)$ using the primers b3.1F and b6R2 [59], and the translation elongation factor $1 \alpha$ (tef 1$)$ using the primers EF595F and EF1160R [60].

We generated amplicons using the following PCR protocol: 4 min at $94^{\circ} \mathrm{C}$; followed by 35 cycles of $25 \mathrm{~s}$ at $94^{\circ} \mathrm{C}$, $30 \mathrm{~s}$ at $56^{\circ} \mathrm{C}\left(r p b 253^{\circ} \mathrm{C}\right.$; ITS and tef $\left.154^{\circ} \mathrm{C}\right)$, and $60 \mathrm{~s}(30 \mathrm{~s}$ ITS and tef 1 ) at $72^{\circ} \mathrm{C}$; followed by a 10 min extension at $72^{\circ} \mathrm{C}$ and an indefinite hold at $4{ }^{\circ} \mathrm{C}$. For all PCR reactions we used the PuReTaq Ready-To-GoTM PCR Beads (GEhealthcare, Waukesha, WI) in a $25 \mu \mathrm{l}$ reaction on an Eppendorf thermocycler (Mastercycler, Hamburg, Germany). We purified the PCR-products using $2 \mu \mathrm{l}$ 10 times diluted ExoSAP-IT (GEhealthcare) to $8 \mu \mathrm{l} \mathrm{PCR}$ product, incubated at $37^{\circ} \mathrm{C}$ for 45 minutes followed by 15 minutes at $80^{\circ} \mathrm{C}$. Cycle sequencing was performed by the CEES ABI-laboratory http://www.mn.uio.no/bio/english/research/about/infrastructure/abi-lab/index.html using the ABI BigDye Terminator sequencing buffer and v3.1 Cycle Sequencing kit (Life Technologies, Carlsbad, CA). Sequences were processed on an ABI 3730 DNA analyser (Life Technologies). Sequences were assembled and edited using BioEdit 7 [61]. All sequences have been deposited in GenBank, and accession numbers are given in Additional file 1.

\section{Datasets}

We aligned the sequences manually using BioEdit 7. We assembled three datasets: Dataset1, consisting of a 2856 basepair (bp) long alignment that includes five genetic regions (nuclear ribosomal LSU, SSU and 5.8S, $r p b 2$ and tef 1), available as Additional file 2; Dataset2, consisting of a $6172 \mathrm{bp}$ long alignment including longer stretches of the above-mentioned markers, available as Additional file 3; Dataset3, consisting of a 918 bp long alignment including LSU only and a total of 38 Serpulaceae accessions (incl. Gymnopaxillus) and Bondarcevomyces for rooting, available as Additional file 4. Due to restricted sequence data, we did not include Gymnopaxillus in the final analyses, but Dataset3 was analyzed to confirm the phylogenetic position of Gymnopaxillus within Serpulaceae and together with Austropaxillus.

\section{Phylogenetic analyses}

Dataset 1 and 2 were analyzed using both Maximum Parsimony (MP) and Bayesian Inference (BI) phylogentic methods. Dataset3 was analyzed using MP only. We performed preliminary MP phylogenetic analyses on each DNA region separately to control visually for betweenregion incongruence prior to concatenation and final phylogenetic analyses. For the MP analyses of the concatenated datasets and Dataset3 we used TNT [62]. We performed heuristic searches with 2000 random addition sequences and TBR branch swapping, saving ten trees per replication. The resulting trees were swapped with 
TBR saving up to 10000 trees. We set the collapsing rule to minimum length $=0$ and random seed was set to "time". Jackknife [63] resampling was performed with 2000 replicates (10 random entry orders and 10 trees saved each repetition), 36\% deletion, absolute frequencies as output, and a cut-off value of $50 \%$.

The best-fit evolutionary models were estimated using the Akaike information criterion (AIC) and the software MrModeltest 2.3 [64] at the Bioportal http://www.bioportal.uio.no. We divided the datasets (Dataset1 and Dataset2) into three partitions: (1) the ribosomal regions (SSU, LSU and 5.8S; collectively nrDNA), (2) $r p b 2$, and (3) tef 1 . The best-fit models for these three parts were: $\mathrm{GTR}+\mathrm{I}+\mathrm{G}$ for the ribosomal regions, $\mathrm{HKY}+\mathrm{I}+\mathrm{G}$ for $r p b 2$, and $\mathrm{SYM}+\mathrm{I}+\mathrm{G}$ for tef 1 .

For the BI analyses, we analyzed a partitioned (according to the above established parts) concatenated alignment of all five nuclear regions using MrBayes 3.1.2 $[65,66]$ at the Bioportal. Bayesian posterior probabilities were determined twice by running one cold and three heated chains for six million generations, saving trees every 1000th generation. To test whether the Markov Chain converged, we monitored the standard deviation of split frequencies (SDSF), and discarded as burn-in the generations prior to the point when the SDSF fell below 0.01 when comparing two independent runs. A 50\% majority rule consensus tree was used to calculate posterior probabilities.

\section{Divergence time estimation}

We used Dataset2 (five DNA regions and 109 accessions) and the computer program Bayesian Evolutionary Analysis Sampling Trees (BEAST) 1.6.1 [21] for estimating the posterior probability distribution of divergence times in Serpulaceae. BEAST co-estimates phylogeny and divergence times [67]. Details about the Bayesian approach used in BEAST have been described by others [12].

Xml-files for the BEAST analyses were constructed using BEAUti 1.6.1 (BEAST package). We analyzed the data under four different treatments; different clock models (strict versus uncorrelated lognormal relaxed [UCLD]), and different prior distributions for the calibrations (exponential versus lognormal). The xml-files of uncorrelated lognormal relaxed clock with exponential and lognormal prior distributions are available as Additional file 5 and Additional file 6, respectively. Because among branch rate heterogeneity within the data was high, we also performed estimations without long-branch taxa (indicated by arrows in Figure 1). However, as divergence time estimates from the analyses with and without long-branch taxa were highly similar, only results from the analysis including the long-branch taxa is presented (see Results). We partitioned the data according to marker and codon position (only the two coding genes; $[1+2], 3)$. Partitioning of data into markers and appropriate codon usage has been shown to produce shorter node heights than unpartitioned analyses [68]. A Yule tree prior was employed in all runs, which assumes a constant speciation rate for each branch in the tree. A lognormal distribution was used for the priors for all calibrated nodes because it fixes the minimum age and allows the maximum age to be sampled following a lognormal distribution with no hard upper limit.

Since there are no known fossils of Serpulaceae we used an extensive outgroup for which fossils are available. We included three primary calibration points (corresponding to the numbered nodes in Figure 2): (1) Quatsinoporites cranhamii Smith, Currah and Stockey from the Early Creatceous (Barremian) [69]; (2) Archeomarasmius leggetti Hibbett, Grimaldi and Donoghue from the early Late Cretaceous [70,71]; and, (3) a permineralized "sulloid" ECM associated with Pinus roots of at least 50 million years [72]. We used the following lognormal settings (Mean in Real Space): (1) logmean $=2.0$, logstdev $=0.5$, and offset $=125.0 ;$ (2) logmean $=2.5$, logstdev $=$ 0.5 , and offset $=90.0$; and, (3) logmean $=1.5, \operatorname{logstdev}=$ 0.5 , and offset $=50.0$. The exponential settings were: (1) mean $=3.0$ and offset $=130.0 ;(2)$ mean $=3.2$ and offset $=90.0$; and, (3) mean $=2.0$ and offset $=50.0$. These lognormal/exponential settings correspond approximately to the following median and 95\% HPD (squarebracketed; numbers rounded off to nearest million): (1) 127 [126-129]/132 [130-139]; (2) 92 (2) 92 [91-95]/92 [90-99]; and (3) 51 [50-53]/51 [50-56]. BEAST may get stuck on local optima because it does not employ a coupled MCMC. Thus, ten additional monophyletic sets of taxa (indicated with black dots on Figure 2) were predefined in order to obtain a topology that corresponds to the phylogeny obtained from a previous study [53] that used a more robust phylogenetic method (e.g. MrBayes) and more taxa. The Markov chains were run for ten million generations, sampling and saving every 1000th tree. Convergence of the chain to stationary distributions was controlled by inspection of the MCMC samples (Trace) in each analysis using the program Tracer 1.5 (BEAST package), and 1000 trees (i.e. 10\%) were discarded as burn-in prior to summarizing the posterior distribution of trees and indentifying the maximum clade credibility (MCC) tree using TreeAnnotator 1.6.1 (BEAST package). Each treatment was analyzed five times to determine if the independent runs converged on the same posterior distribution. In order to obtain effective sample sizes (ESS) of more than 100 for all parameters, we combined the log output files from separate runs with the same treatment using LogCombiner 1.6.1 (BEAST package). To compare the different clock treatments, we monitored the "CoefficientOfVariation" 


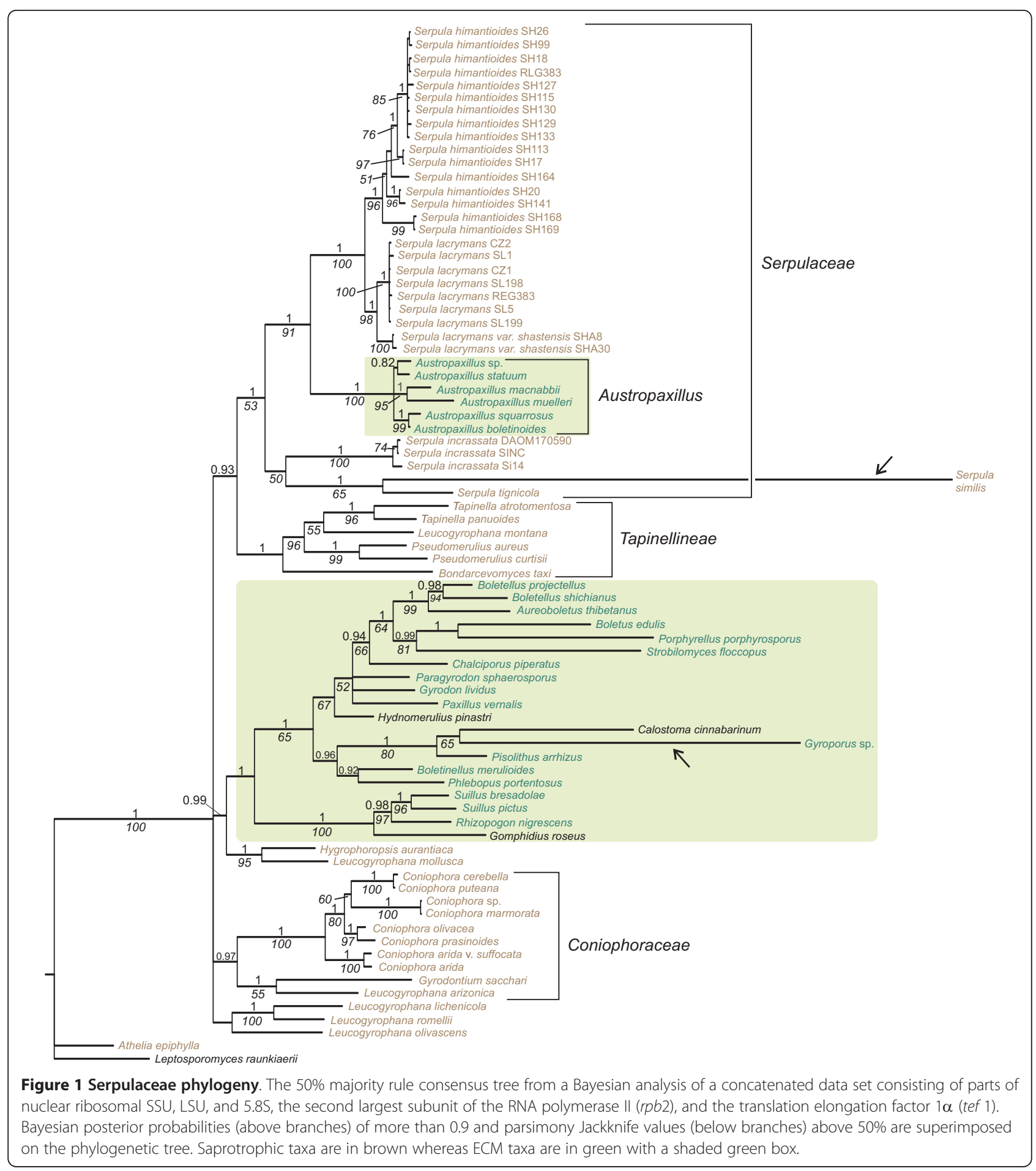

for each partition in the relaxed clock analyses, and discarded a strict clock evolution if the distribution did not bump up against zero.

\section{Ancestral area analyses}

We predefined unit areas based on present-day distributions of Serpulaceae taxa. The following seven unit areas were used: (A) western North America; (B) eastern North America; (C) western Eurasia; (D) eastern Eurasia; (E) southern South America; (F) Australia + New Zealand; and, (G) Old World Tropical. For each terminal taxon we coded the unit area(s) in which it presently occurs. The variety Serpula lacrymans var. shastensis has been recorded once in the Caucasus [43], outside its 


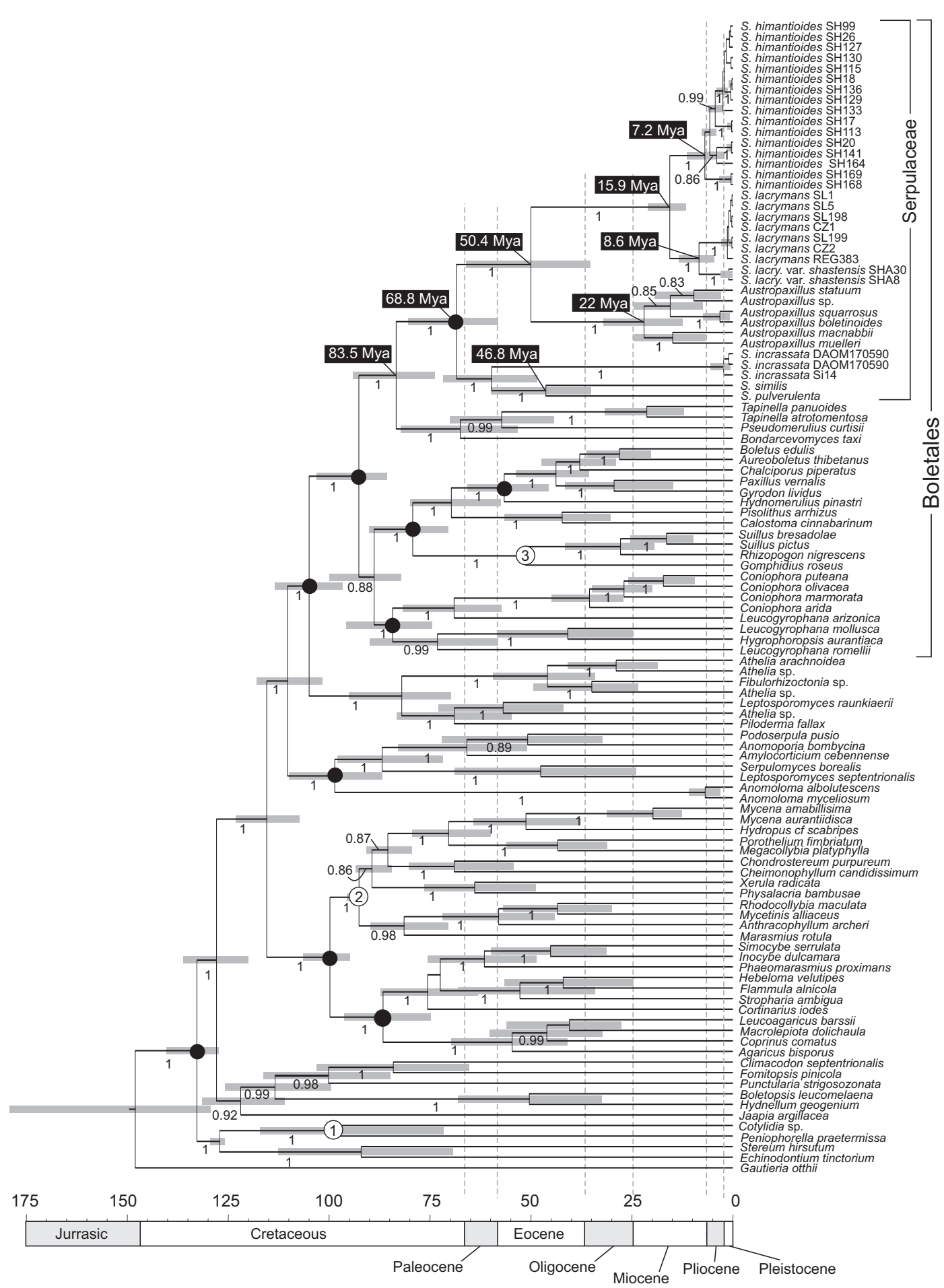

Figure 2 Molecular dating analysis. The MCC chronogram of an Agaricomycetidae subset, with main focus on Boletales taxa, obtained from divergence time estimation using BEAST. Grey bars denote the $95 \%$ highest posterior density (HPD) intervals of the posterior probability distribution of node ages. Calibrated nodes are numbered (see text for details). Bayesian posterior probabilities of more than 0.8 are indicated on branches. Numbers on the scale axis are in millions of years before present (MyBP). Black dots at nodes indicate monophyly-contraints used in the BEAST analysis. 
range as defined in this study. However, this observation has not been confirmed by other studies.

We used two alternative event-based ancestral area methods: (1) a Bayesian approach to dispersal-vicariance analysis (DIVA [73]) as implemented in the computer software Reconstruct Ancestral States in Phylogenies (RASP [74]) and, (2) the dispersal-extinction-cladogenesis analysis (DEC [75]) implemented in the computer program LAGRANGE. The Bayesian approach in RASP is built on the source code of MrBayes 3.1.2, and is a generalization of the methods used in Olsson et al. [76] and Sanmartin et al. [77]. We chose the F81 model for the Bayesian MCMC analyses, allowing for different rates of change among ancestral areas. The Bayesian posterior probabilities were determined twice by running 10 chains fifty thousand generations, saving reconstructions every 100th generations.

The ancestral area analyses were conducted on the posterior distribution of dated Serpulaceae trees estimated from BEAST. RASP analyses were carried out using $10^{3}$ randomly selected trees from BEAST.

The DEC analyses in LAGRANGE enables maximum likelihood estimation of range inheritance scenarios at cladogenesis events by modelling transitions between discrete states (ranges) along phylogenetic branches as a function of time. The DEC script was produced using a web-based analysis configuration tool available from http://www.reelab.net/lagrange/configurator/index.

\section{Results Phylogeny}

In the MP analysis of Dataset1, we obtained 469 most parsimonious trees (MPTs) of 4485 steps and with a reconciled consistency index (RC) of 0.2 and a homoplasy index (HI) of 0.69. Our results from the BI and MP analyses were largely congruent, but variously resolved. The Bayesian 50\% majority rule consensus tree is presented with branch support (posterior probabilities [PP] and parsimony jackknifing [JK]) superimposed in Figure 1. Results render Serpulaceae monophyletic with Tapinellineae as phylogenetic sister (Figure 1). The Serpulaceae/ Tapinellineae group consists of brown rot species except for the Austropaxillus clade. The brown rot species belonging to Coniophora and Coniophoraceae appear as a monophyletic group separated from the Serpulaceae/ Tapinellineae clade (Figure 1).

The saprotrophic Serpula himantioides and S. lacrymans appear as sister taxa in the phylogeny and together form a monophyletic group (Figure 1). Serpula lacrymans is further subdivided in two lineages representing the two described varieties, var. lacrymans and var. shastensis (see [43]). Austropaxillus forms a monophyletic sister to the $S$. lacrymans/S. himantioides group that makes Serpula paraphyletic as currently circumscribed (Figure 1).
A clade comprising the saprotrophic species Serpula incrassata, S. pulverulenta and S. similis is recovered as sister to all other Serpulaceae (Figure 1). The branch leading to $S$. similis is very long, indicating an increased rate of molecular evolution in this lineage.

The MP analysis of Dataset3 produced 16 MTPs of 311 steps, an RC of 0.90 , and an $\mathrm{HI}$ of 0.06 . The strict consensus tree with $\mathrm{JK}$ values superimposed is presented in the Additional files. A monophyletic Gymnopaxillus group renders Austropaxillus paraphyletic (Additional file 7, Figure. S1).

\section{Divergence time estimation}

The posterior distribution of the "CoefficientOfVariation" suggests rejection of a strict clock for all gene partitions. Relaxed (UCLD) clock analyses with lognormal versus exponential priors for the calibrations estimated rather similar age estimates of Serpulaceae divergences (Table 1). The maximum clade credibility $(\mathrm{MCC})$ tree obtained from the relaxed clock/lognormal treatment is presented in Figure 2. A subsection of this chronogram, including Serpulaceae only, is presented in Figure 3. Mean nodal age estimates for numbered nodes in Figure 3 and their respective $95 \%$ highest posterior density (HPD) intervals are reported in Table 1.

According to the estimated divergence times, Serpulaceae diverged from the Tapinellineae during the Late Cretaceous, and the mean crown-group age of Serpulaceae was estimated to about 64 (80-58) MyBP (Figure 2; Table 1; Figure 3, clade 1). The three Serpula species, S. incrassata, S. similis and S. pulverulenta (Figure 3, clade 2) appear to be the oldest species within Serpulaceae, with divergences among sampled species evident from the Late Cretaceous to Early Eocene (71-48 MyBP).

The divergence between the ECM group and the brown rot species (Austropaxillus vs. S. lacrymans and S. himatioides) is estimated to have happened between the Late Cretaceous to Late Eocene (66-35 MyBP; Figure 3, node 5). The posterior mean crown-group age of Austropaxillus is approximately 22 (32-12) My (Figure 3, node 6). Subsequent speciation events of sampled Austropaxillus species seem to suggest a fairly constant rate of speciation. The divergence of the two widely distributed Serpula lacrymans and S. himantioides is estimated to have occurred in Miocene; the mean age estimate being 16 MyBP (Figure 3, node 9). Intraspecific diversification leading to varieties and cryptic species within S. lacrymans and S. himantioides is estimated to have occurred during the Miocene and Pliocene (Figure 3).

\section{Ancestral area analyses}

The inferred historical biogeographic scenarios from analyses using DEC (from LAGRANGE) and RASP are 
Table 1 Results from phylogenetic, dating and ancestral area analyses

\begin{tabular}{|c|c|c|c|c|c|c|c|}
\hline Node & $\begin{array}{l}\text { Branch } \\
\text { support } \\
1\end{array}$ & $\begin{array}{l}\text { Node age } \\
\text { lognormal }\end{array}$ & $\begin{array}{l}95 \% \text { HPD } \\
\text { lognormal }\end{array}$ & $\begin{array}{l}\text { Node age } \\
\text { exponential }\end{array}$ & $\begin{array}{l}\text { 95\% HPD } \\
\text { exponential }\end{array}$ & RASP & DEC (LAGRANGE) \\
\hline 1 & $1 / 51$ & 68.75 & $57.93-80.08$ & 69.46 & $58.36-81.25$ & - & - \\
\hline 2 & $0.66 /-$ & 60.07 & 48.23-71.46 & 60.27 & $48.65-72.11$ & $A B(0.576), A B C(0.400)$ & $\begin{array}{l}A(0.029), B(0.022), \\
E(0.014), F(0.012) \ldots\end{array}$ \\
\hline 3 & $1 / 61$ & 56.80 & $34.97-59.63$ & 46.64 & $33.5-59.03$ & $\begin{array}{l}A B C(0.551), A B(0.316), B C(0.032), A C \\
(0.031), B(0.018), A(0.018), A B C G(0.016)\end{array}$ & $\begin{array}{l}A(0.035), B(0.033), \\
G(0.027), C(0.023) \ldots\end{array}$ \\
\hline 4 & $1 / 100$ & 2.61 & $0.45-5.41$ & 2.67 & $0.62-6.24$ & $A B(0.982), A B C(0.0163)$ & $\begin{array}{l}A(0.035), B(0.033), \\
G(0.027), C(0.023) \ldots\end{array}$ \\
\hline 5 & $1 / 90$ & 50.44 & $35.15-65.82$ & 50.72 & $33.61-67.35$ & $\begin{array}{l}A(0.706), A B(0.125), A C B(0.038), C(0.018), \\
A E(0.014), A B C(0.010)\end{array}$ & $\begin{array}{l}A(0.031), E(0.024), \\
F(0.021), B(0.010)\end{array}$ \\
\hline 6 & $1 / 100$ & 22.03 & $12.40-31.92$ & 22.33 & $13.09-31.68$ & $\begin{array}{l}F(0.494), E(0.241), A(0.092), E F(0.079), A F \\
(0.030), A E(0.015)\end{array}$ & $\begin{array}{l}A(0.029), E(0.028), \\
F(0.025), D(0.013) \ldots\end{array}$ \\
\hline 7 & $1 / 95$ & 15.22 & $6.63-24.43$ & 15.40 & $7.48-24.56$ & $F(0.987)$ & $\begin{array}{l}F(0.198), E(0.044) \\
E F(0.017)\end{array}$ \\
\hline 8 & $-/ 100$ & 15.71 & $7.46-24.47$ & 15.87 & $8.23-25.38$ & $E(0.994), E F(0.078), F(0.017)$ & $\begin{array}{l}E(0.130), F(0.096), \\
\operatorname{EF}(0.037)\end{array}$ \\
\hline 9 & $1 / 100$ & 15.88 & $11.63-21.00$ & 16.25 & $11.53-21.06$ & $\mathrm{~A}(0.941), \mathrm{AE}(0.025), \mathrm{AD}(0.011)$ & $\begin{array}{l}\text { A (0.044), E (0.024), } \\
F(0.019), D(0.013) \ldots\end{array}$ \\
\hline 10 & $1 / 98$ & 8.60 & $4.45-13.23$ & 8.81 & $4.63-13.65$ & $\mathrm{~A}(0.905), \mathrm{AD}(0.071), \mathrm{D}(0.015)$ & $\begin{array}{l}A(0.140), D(0.026), \\
E(0.022)\end{array}$ \\
\hline 11 & $1 / 100$ & 1.19 & $0.05-2.91$ & 1.32 & $0.11-3.12$ & A $(0.997)$ & $\begin{array}{l}A(0.251), D(0.079), \\
A D(0.035)\end{array}$ \\
\hline 12 & $1 / 100$ & 1.44 & $0.45-2.88$ & 1.49 & $0.22-2.94$ & $\mathrm{D}(0.941), \mathrm{AD}(0.055)$ & $\begin{array}{l}D(0.260), A(0.094), \\
A D(0.031)\end{array}$ \\
\hline 13 & $1 / 92$ & 7.29 & $4.29-11.31$ & 7.70 & $4.31-11.67$ & $A(0.883), A E(0.090), E(0.019)$ & $\begin{array}{l}A(0.140), D(0.026), \\
E(0.022)\end{array}$ \\
\hline
\end{tabular}

Results from various analyses of Dataset2 (node numbers refer to Figure. 3): branch support, mean node ages, the 95\% highest posterior density values (HPD; depicted as grey bars in Figure. 3) from analyses using a relaxed clock with lognormal and exponential settings, and inferred ancestral areas at internal nodes (RASP) and branches (DEC; relative probability of an area reported for branch leading to numbered node). Areas with a relative probability of $>0.01$ in the DEC and RASP analyses are reported. Unit areas: A = western North America, B = eastern North America, C = western Eurasia, D = eastern Eurasia, E = southern South America, F = Australia + New Zealand, G = Old World Tropical.

${ }^{1}$ Bayesian posterior probability to the left and parsimony jackknife support to the right hand side of slash.

${ }^{2}$ Estimated age of divergence events in millions of years before present (depicted as a chronogram in Figure. 2).

${ }^{*}$ Not present for maxareas $=2$

summarized in Table 1 and Figure 3. The inferred ancestral areas at internal nodes estimated using the Bayesian RASP correspond largely to the results obtained from the maximum likelihood estimates in DEC. RASP estimated more combined ancestral areas than DEC, and the RASP estimates have generally a higher relative probability for each ancestral area (Table 1).

The maximum likelihood reconstruction of ancestral areas for the internal nodes of Serpulaceae show that the most recent common ancestor (tmrca) of clades 2-4 (Figure 3, node 5) most likely appeared in western North America during the Paleocene-Eocene boundary. Range expansion of one daughter lineage, Austropaxillus (Figure 3, clade 2), into South America, Australia and/or New Zealand some time during the Eocene to Mid Miocene followed this. The divergence into one mainly southern South American clade (node 8) and one Australian/New Zealand clade (node 7) is estimated to have happened about 15 (24-7) MyBP. The second daughter lineage, tmrca of $S$. himantioides and S. lacrymans (Figure 3, clades 3-4, node 9), most likely occurred in western North America during the Early Eocene to Mid Miocene.

\section{Discussion}

\section{Molecular phylogenetics of Serpulaceae}

Our results based on five nuclear DNA regions corroborate the monophyly of Serpulaceae sensu Jarosch [50]. Moreover, a close relationship between the saprotrophic Serpula and the ectomycorrhizal Austropaxillus is supported, as already indicated in previous studies based on more restricted taxon samplings and fewer genetic markers $[37,50]$. Gymnopaxillus nested within the Australian Austropaxillus clade (Additional file 7, Figure. S1) in the nrLSU analysis. Traditionally, Serpula has been recognised as a member of Coniophoraceae [39,78]. Our molecular results clearly show that Serpula is only distantly related to Coniophora, supporting the treatment of Serpulaceae [50] as a separate family that comprises 

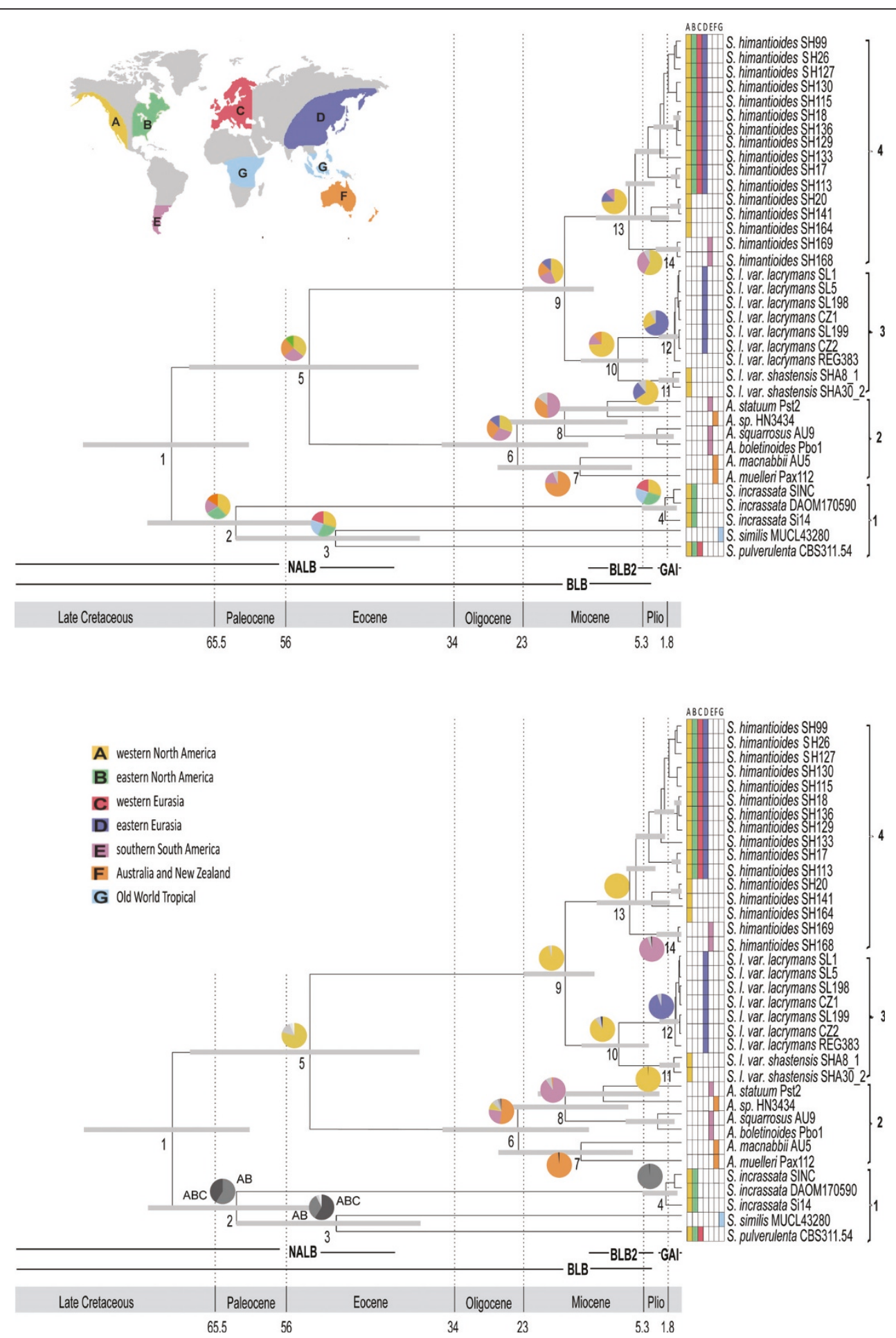

Figure 3 Serpulaceae chronogram. Out-cut of Serpulaceae from the chronogram presented in Figure. 2 (the maximum clade credibility tree obtained from divergence time estimation using BEAST). Grey bars denote the $95 \%$ highest posterior density (HPD) intervals of the posterior probability distribution of node ages. Nodes that are referred to in the text and in Table 1 are numbered and clades that are referred to in the text are numbered 1-4 to the right. Numbers on the scale axis are in millions of years before present (MyBP). Pie diagrams show the ancestral distributions estimated for internal nodes using a) DEC (LAGRANGE) and b) RASP. Only ancestral areas with probability $>0.01$ are shown on the figure. Grey colour on pie diagrams indicate combined ancestral areas, and for nodes where a combined ancestral area is estimated as highly probable the combination is written next to the pie diagram. Abbreviations: Pli $=$ Pliocene, NALB $=$ North American landbridge, BLB $=$ Bering landbridge, BLB2 = Bering landbridge 2, and GAl = Great American interchange. 
the three genera Austropaxillus, Gymnopaxillus and Serpula. That Austropaxillus and Gymnopaxillus are nested within Serpula suggests taxonomic changes are needed to accommodate this monophyly. Unfortunately we were unable to include samples from South American Gymnopaxillus species, so our results call for further analyses including more markers and samples from this group.

\section{Historical biogeography of Serpulaceae}

Our results indicate a Late Cretaceous origin of extant Serpulaceae, between 94 and 74 MyBP (Figure 2) in temperate North America (Figure 3). The Gymnosperm genus Pinus is the main substrate of Serpulaceae in the Northern Hemisphere. Pinus, is estimated to have evolved during the Cretaceous, between 155 and 87 MyBP [79]. Thus the age of Pinus corresponds well with the timing of the evolution of Serpulaceae on Pinus wood. Moreover, the fossil record supports the presence of Pinaceae members in the high-latitude and high-altitude regions of North America during the early Cenozoic [72]. This supports our result, as the main host of Serpulaceae was available at the time of origin.

The initial divergence of extant Austropaxillus taxa into one mainly southern South American clade and one Australian/New Zealand clade about 22 (32-12) MyBP (Figure 3, node 6) must represent a long distance dispersal event, and is consistent with a biogeographical tract referred to by Crisp et al as a pan-temperate tract [80]. Nor does the relatively recent split between northern and southern hemisphere taxa in Serpulaceae support an ancient Gondwanan distribution of Austropaxillus. However, there have been fierce discussions of the time and climatic conditions of the Gondwanan break-up [81]. Land bridges have been suggested between Antarctica and Australia up until 28 MyBP $[82,83]$. During this period Antarctica was probably glaciated [81] and may have been too hostile for temperate fungi. Thus, even if we cannot rule out vicariance, we consider long distance dispersal a more plausible explanation. Moreover, the divergence times estimated within Serpulaceae can be expected to be somewhat younger due to the node density effect [84], supporting a long-distance dispersal event.

The divergence between Austropaxillus macnabbi from New Zealand and A. muelleri from Tasmania (Figure 3, node 7) must have resulted from a more recent dispersal event. New Zealand was separated from South America and Australia about 80 MyBP [82], i.e. about 60 My years before the split at node 7 (24-7 MyBP). Interestingly, the same recent divergence between species from New Zealand and Australia have also been found for Nothofagus [85], the host of Austropaxillus, and its fungal parasite Cyttaria [86]. Long distance dispersal is also suggested in order to explain the divergence between Austropaxillus sp. from Tasmania and A. statuum from southern South America (Figure 3). However, as the sister-relationship between the two species is weakly supported, more data is needed to confirm or reject this long distance dispersal hypothesis. Additional fungal disjunctions that are too young to be caused by Gondwanan breakup, and thus are explained by long-distance dispersal have been reported elsewhere (e.g. $[10,11,18])$.

Assuming western North America as the true ancestral area at node 5 (Figure 3), the presence of southern South American species in both clade 2 (Austropaxillus) and clade 4 (S. himantioides) must be explained by independent long-distance dispersal events. This can be concluded, because Laurasia (incl. North America) and Gondwana (incl. southern South America) were separated by the east-west Tethyan seaway from the latest Jurassic (c $150 \mathrm{MyBP}$ ) to the end of Pliocene (c 3 MyBP; [87]). This seaway represented a major dispersal barrier to most terrestrial organisms. Not until the establishment of the Great American Interchange (GAI; ca. $3 \mathrm{MyBP}$ ) was there land connection between North and South America (Figure 3). Although the two dispersals happened at different times, none correspond to time periods of land-connection between North and South America. Moreover, the large distributional gap between North American and southern South American sister-taxa of Serpula (see inset map in Figure 3) favours long distance dispersals to historically continuous distributions with subsequent vicariance. Still, the distinctness of the disjunct lineages indicates that such inter-area dispersals are not frequent. Nevertheless, historical long distance dispersal has been reported in several mycogeographic studies (e.g. $[11,18,88]$ ), and dispersal between northern and southern temperate regions of the world seems to have occurred in other fungal groups also (e.g. $[10,20])$ and plants [80].

All taxa represented in clade 3 (Figure 3 ) belong to the same morphospecies, Serpula lacrymans. The chronogram shows that the divergence of the two varieties occurred about 9 (13-4) MyBP (Figure 3, node 10). The presence of western North American and eastern Eurasian phylogenetic sister-taxa are indicative of a trans-Beringian distribution of their most recent common ancestor with subsequent vicariance (Figure 3). About 14-3.5 MyBP, there was continuous boreal forests across Beringia (Figure 3, BLB2; [89]). It seems likely therefore, that S. lacrymans had a continuous distribution from northern North America and into Eurasia and that var. lacrymans became differentiated from var. shastensis due to Beringan vicariance (Figure 3). Comparison of ancient permafrost-preserved (plant-parasitic) fungal DNA from north-eastern Siberia to modern tundra macrofungi indicate a shift in fungal diversity following the last ice-age [90], a scenario probably 
reiterated many times during the Pleistocene producing allopatric populations. Migration across a North Atlantic landbridge (NALB) has sometimes been used as an alternative explanation to Nearctic-Palearctic disjunctions, but this bridge disappeared by Mid Eocene (Figure 3; [89]) i.e. about $30 \mathrm{My}$ before the estimated divergence of the two varieties. Historical Beringian distributions with subsequent vicariance and range expansion southwards have been shown also in Amanita [91] and Tricholoma [92], and we suspect that additional Beringian disjunctions would have been identified if the Holarctic was not treated as a single area in mycogeography (see e.g. [11,20]).

\section{Evolution of nutritional modes in Serpulaceae}

According to our results, the transition to ECM has happened only once in Serpulaceae, in the lineage leading to Austropaxillus (Figure 1). Transition from a saprotrophic to ectomycorrhizal nutritional mode is a common ecological transition [28]. The common ancestor of Austropaxillus and Gymnopaxillus diverged from the saprotrophic clade about 50 MyBP. The temperature decline and a drier climate in the end of the Eocene and the onset of Oligocene may have promoted this transition from saprotrophy to mycorrhiza. When growing in nature, S. lacrymans mainly occurs on substrates in close contact with the ground (H. Kauserud, personal observations), and it seems to be a geophilous fungus that may transport water from the ground and into the substrate. Whether such an adaptation could be a first step towards mycorrhizal symbiosis is a subject for future investigation.

Our results indicate that the mycorrhizal Austropaxillus/ Gymnopaxillus lineage diverged from the saprotrophic S. lacrymans/S. himantioides group about 50 (66-35) MyBP and that the radiation of extant Austropaxillus/ Gymnopaxillus taxa commenced about 22 (32-12) MyBP (Figure 3). A more recent split between Austropaxillus and S. lacrymans (53.1-15 MyBp) was suggested in a recent paper analyzing a smaller dataset of genomesequenced fungi [93]. The differences between these studies can probably largely be explained by taxon sampling. Because of the focus of this study, we have included more samples from the Serpulaceae compared to other fungal families; this could give a somewhat older age according to the node density effect [84] as argued above. Fossilized ECM demonstrates that ECM associations had evolved at least 50 MyBP, probably with a Pinus-host [94]. It has been suggested that the radiation of ECM fungi happened as the obligate ECM hosts (Pinaceae and Fagales) became dominant in temperate forests as a consequence of drying and cooling from the Late Eocene $[16,20]$.

\section{Conclusions}

Our analyses support the monophyly of Serpulaceae sensu Jarosch and a Late Cretaceous origin of the family. A single transition from brown rot to ECM occurred within the Serpulaceae. The dating analysis indicates that this transition happened between 50 and $22 \mathrm{MyBP}$. Most Serpulaceae divergences seem to have happened within continents (Australia, South American, and North America). A combination of long distance dispersals for the southern hemisphere taxa and vicariance for the northern hemisphere taxa is used to explain the distribution of extant Serpulaceae taxa. The dating analysis indicates that the divergence of the two varieties of Serpula lacrymans occurred between 13 and 4 MyBP due to Beringian vicariance.

\section{Additional material}

Additional file 1: Specimens included in this study. A table including origin, Isolate ID and GenBank accession numbers for each specimen in the study.

Additional file 2: Allignment of Dataset1. A 2856 bp allignment of the five nuclear regions 5.8S, nrLSU, nrSSU, rpb2, tef1 for 79 accessions of Serpulaceae taxa including an extensive boletalean outgroup (41 accessions) and two athelialean accessions for rooting the tree.

Additional file 3: Allignment of Dataset2. A $6172 \mathrm{bp}$ allignment of the five nuclear regions 5.8S, nrLSU, nrSSU, rpb2, tef1 for 109 accessions of Boletales and nine additional fungal orders.

Additional file 4: Allignment of Dataset3. Allignment of the nuclear ribosomal LSU region for 39 accessions of the Serpulaceae and one outgroup.

Additional file 5: $\mathrm{Xml}$ file using an exponential prior distribution for Dataset2. An .xml file created by BEAUti 1.6.1 for analyses of the data using an uncorrelated exponential relaxed molecular clock in BEAST.

Additional file 6: Xml file using a lognormal prior distribution for Dataset2. An .xml file created by BEAUti 1.6.1 for analyses of the data using an uncorrelated lognormal relaxed molecular clock in BEAST.

Additional file 7: Serpulaceae nrLSU phylogeny including

Gymnopaxillus. Strict consensus tree from a maximum parsimony analysis of the nuclear ribosomal LSU region of 38 Serpulaceae taxa. Bondarcevomyces taxi was used as outgroup. The 16 most parsimonious trees (MPTs) were 311 steps long and had a rescaled consistency index of 0.90 and homoplasy index of 0.06 . Jackknife support values (2000 replicates) are superimposed on the branches, showing that the included Gymnopaxillus spp. (grey shading) are nested within Austropaxillus with high support.

\section{Acknowledgements}

We acknowledge Margit Jarosch and Fungal Herbarium of New Zealand (PDD) for providing study material of Austropaxillus, Andreas Bresinsky for helpful information about Austropaxillus. Teresa Lebel, Marie L. Davey and two referees are acknowledged for helpful comments that improved the manuscript, and the Research Council of Norway and the University of Oslo for financial support. MaB was supported by AFTOL2 (DEB-0732968).

\section{Author details}

'Microbial Evolution Research Group (MERG), Department of Biology, University of Oslo, P.O. Box 1066 Blindern, N-0316 Oslo, Norway. ${ }^{2}$ Department of Biology, Clark University, Worcester, Massachusetts 01610, USA. ${ }^{3}$ National Centre for Biosystematics, Natural History Museum, University of Oslo, P.O. Box 1172 Blindern, N-0318 Oslo, Norway.

Authors' contributions

IS and MiB participated in analyzing the data and wrote most of the manuscript. IBE generated data, established alignments, participated in 
analyzing the data, and wrote parts of the manuscript. MaB generated data, established alignments and commented upon the manuscript. TC participated in analyzing the data and commented upon the manuscript. HK conceived of the study, and participated in its coordination and helped to draft the manuscript. All authors read and approved the final manuscript.

Received: 15 March 2011 Accepted: 4 August 2011

Published: 4 August 2011

\section{References}

1. Peay KG, Bidartondo Ml, Arnold AE: Not every fungus is everywhere: scaling to the biogeography of fungal-plant interactions across roots, shoots and ecosystems. New Phytologist 2010, 185:878-882.

2. Lumbsch TH, Buchanan PK, May TW, Mueller GM: Phylogeography and biogeography of fungi. Mycological Research 2008, 112:423-424

3. Taylor JW, Turner E, Townsend JP, Dettman JR, Jacobson D: Eukaryotic microbes, species recognition and the geographic limitation of species: examples from the kingdom fungi. Proceedings of the Royal Society $B$ : Biological Sciences 2006, 361:1947-1963.

4. O'Donnell K, Rooney AP, Mills GL, Kuo M, Weber NS: Phylogeny and historical biogeography of true morels (Morchella) reveals an early Cretaceous origin and high continental endemism and provincalism in the Holarctic. Fungal Genetics and Biology 2011, 48:252-265

5. Martin F, Díez J, Dell B, Delaruelle C: Phylogeography of the ectomycorrhizal Pisolithus species as inferred from nuclear ribosomal DNA ITS sequences. New Phytologist 2002, 153:345-357.

6. Parrent JL, Garbelotto M, Gilbert GS: Population genetic structure of the polypore Datronia caperata in fragmented mangrove forests. Mycological Research 2004, 108:403-410

7. Wiley EO: Vicariance biogeography. Annual Review of Ecology and Systematics 1988, 19:513-542.

8. de Queiroz A: The resurrection of oceanic dispersal in historical biogeography. Trends in ecology \& evolution 2005, 20:68-73.

9. Halling RE, Osmundson TW, Neves M-A: Pacific boletes: Implications for biogeographic relationships. Mycological Research 2008, 112:437-447.

10. Hosaka K, Castellano MA, Spatafora JW: Biogeography of Hysterangiales (Phallomycetidae, Basidiomycota). Mycological Research 2008, 112:448-462.

11. Moncalvo JM, Buchanan PK: Molecular evidence for long distance dispersal across the Southern Hemisphere in the Ganoderma applanatum-australe species complex (Basidiomycota). Mycological Research 2008, 112:425-436.

12. Berbee ML, Taylor JW: Dating the molecular clock in fungi-how close are we? Fungal Biology Reviews 2010, 24:1-16.

13. Allwood J, Gleeson D, Mayer G, Daniels S, Beggs JR, Buckley TR: Support for vicariant origins of the New Zealand Onychophora. Journal of Biogeography 2010, 37:669-681.

14. Benavides E, Baum R, Snell HM, Snell HL, Sites JW: Island biogeography of Galapagos lava lizards (Tropiduridae: Microlophus): species diversity and colonization of the archipelago. Evolution 2009, 63:1606-1626.

15. Berbee ML, Taylor JW: Dating the evolutionary radiations of the true fungi. Canadian Journal of Botany 1993, 71:1114-1127.

16. Bruns TD, Szaro TM, Gardes M, Cullings KW, Pan JJ, Taylor DL, Horton TR, Kretzer A, Garbelotto M, Li Y: A sequence database for the identification of ectomycorrhizal basidiomycetes by phylogenetic analysis. Molecular Ecology 1998, 7:257-272.

17. Geml J, Geiser DM, Royse DJ: Molecular evolution of Agaricus species based on ITS and LSU rDNA sequences. Mycological Progress 2004, 3:157-176.

18. Hibbett D: Shiitake mushrooms and molecular clocks: historical biogeography of Lentinula. Journal of Biogeography 2001, 28:231-241.

19. Jeandroz S, Murat C, Wang Y, Bonfante P, Le Tacon F: Molecular phylogeny and historical biogeography of the genus Tuber, the "true truffles". Journal of Biogeography 2008, 35:815-829.

20. Matheny PB, Aime MC, Bougher NL, Buyck B, Desjardin DE, Horak E, Kropp BR, Lodge DJ, Soytong K, Trappe JM, Hibbett DS: Out of the Palaeotropics? Historical biogeography and diversification of the cosmopolitan ectomycorrhizal mushroom family Inocybaceae. Journal of Biogeography 2009, 36:577-592.

21. Drummond AJ, Rambaut A: BEAST: Bayesian evolutionary analysis by sampling trees. BMC Evolutionary Biology 2007, 7:214.
22. Hibbett D: A Phylogenetic overview of the Agaricomycotina. Mycologia 2006, 98:917-925.

23. James TY, Kauff F, Schoch CL, Matheny PB, Hofstetter V, Cox CJ, Celio G, Gueidan C, Fraker E, Miadlikowska J, Lumbsch TH, Rauhut A, Reeb V, Arnold EA, Amtoft A, Stajich JE, Hosaka K, Sung G-H, Johnson D, O'Rourke B, Crockett M, Binder M, Curtis JM, Slot JC, Wang Z, Wilson AW, Schüler A, Longcore JE, O'Donnell K, Mozley-Standridge S, et al: Reconstructing the early evolution of Fungi using a six-gene phylogeny. Nature 2006, 443:818-822.

24. Binder M, Hibbett DS: Higher-level phylogenetic relationships of Homobasidiomycetes (mushroom-forming fungi) inferred from four rDNA regions. Molecular Phylogenetics and Evolution 2002, 22:76-90.

25. Hibbett DS: After the gold rush, or before the flood? Evolutionary morphology of mushroom-forming fungi (Agaricomycetes) in the early 21st century. Mycological Research 2007, 111:1001-1018.

26. Hibbett D, Matheny PB: The relative ages of ectomycorrhizal mushrooms and their plant hosts estimated using Bayesian relaxed molecular clock analyses. BMC Biology 2009, 7:13.

27. Smith SE, Read DJ: Mycorrhizal symbiosis. Oxford: Elsevier; 2008.

28. Tedersoo L, May TW, Smith ME: Ectomycorrhizal lifestyle in fungi: global diversity, distribution, and evolution of phylogenetic lineages. Mycorrhiza 2010, 20:217-263.

29. Read DJ, Perez-Moreno J: Mycorrhizas and nutrient cycling in ecosystems-a journey towards relevance? New Phytologist 2003, 157:475-492.

30. Selosse MA, Le Tacon F: The land flora: a phototroph-fungus partnership? Trends in Ecology \& Evolution 1998, 13:15-20.

31. Brundrett M: Coevolution of roots and mycorrhizas of land plants. New Phytol 2002, 154:275-304

32. Boddy L, Frankland JC, van West P, eds: Ecology of saprotrophic Basidiomycetes. Oxford: Elsevier; 2008.

33. Hibbett DS, Donoghue MJ: Analysis of character correlations among wood decay mechanisms, mating systems, and substrate ranges in Homobasidiomycetes. Systematic Biology 2001, 50:215-242.

34. Hibbett D, Gilbert L-B, Donoghue M: Evolutionary instability of ectomycorrhizal symbioses in basidiomycetes. Nature 2000, 407:506-508

35. Binder M, Hibbett DS, Larsson K-H, Langer E, Langer G: The phylogenetic distribution of resupinate forms across the major clades of mushroomforming fungi (Homobasiodiomycetes). Systematic Biodiversity 2005, 3:113-157.

36. Hibbett $\mathrm{D}$, Binder M: Evolution of complex fruiting-body morphologies in homobasidiomycetes. Proceedings of the Royal Society B: Biological Sciences 2002, 269:1963-1969.

37. Binder M, Hibbett DS: Molecular systematics and biological diversification of Boletales. Mycologia 2006, 98:971-981.

38. Falck R: Die Meruliusfäule des Bauholzes. Neue Untersuchungen über Unterscheidung, Verbreitung, Entstehung und Bekämpfung des echten Hausscwammes. Jena: G. Fischer; 19126.

39. Hallenberg N, Eriksson J: The Lachnocladiaceae and Coniophoraceae of North Europe. Oslo: Fungiflora A/S; 1985.

40. Bech-Andersen J: The dry rot fungus and other fungi in houses. Holte, Denmark: Hussvamp Laboratoriet; 1995.

41. Cooke WB: The genera Serpula and Meruliporia. Mycologia 1957, 49:197-225.

42. Harmsen L, Bakshi BK, Choudhury TG: Relationship between Merulius lacrymans and M. himantioides. Nature 1958, 181:1011.

43. Kauserud H, Svegården IB, Saetre G-P, Knudsen H, Stensrud $\varnothing$, Schmidt O, Doi S, Sugiyama T, Högberg N: Asian origin and rapid global spread of the destructive dry rot fungus Serpula lacrymans. Molecular Ecology 2007, 16:3350-3360.

44. Carlsen T, Engh IB, Decock C, Rajchenberg M, Kauserud H: Multiple cryptic species with divergent substrate affinities in the Serpula himantioides species complex. Fungal Biology 2011, 115:54-61.

45. Kauserud H, Stensrud $\varnothing$, Decock C, Shalchian-Tabrizi K, Schumacher T: Multiple gene genealogies and AFLPs suggest cryptic speciation and long-distance dispersal in the basidiomycete Serpula himantioides (Boletales). Molecular Ecology 2006, 15:421-431.

46. Harmsen L: De danske Merulius-arter. Botanisk Tidsskrift 1954, 50:146-162.

47. Christiansen MP: Danish resupinate fungi. Part II: Homobasidiomycetes. Dansk Botanisk Arkiv 1960, 19:57-388. 
48. Carlier F-X, Bitew A, Castillo G, Decock C: Some Coniophoraceae (Basidiomycetes, Boletales) from the Ethiopian highlands: Coniophora bimacrospora, sp. nov. and a note on the phylogenetic relationships of Serpula similis and Gyrodontium. Cryptogamie, Mycologie 2004, 25:261-275.

49. Ginns J: The genus Merulius IV. Species proposed by Berkeley and Curtis, and by Berkeley and Broome. Mycologia 1971, 63:219-236.

50. Jarosch M: Zur Molekularen Systematik der Boletales: Coniophorineae, Paxillineae und Suillineae. Berlin-Stuttgart: J. Cramer; 2001191.

51. Claridge A, Trappe J, Castellano M: Australasian truffle-like fungi. X Gymnopaxillus (Basidiomycota, Austropaxillaceae). Australian Systematic Botany 2001, 14:273-281.

52. Bresinsky $A$, Jarosch $M$, Fischer $M$, Schönberger I, Wittmann-Bresinsky B: Phylogenetic relationships within Paxillus s.l. (Basidiomycetes, Boletales): Separation of a Southern Hemisphere Genus. Plant Biology 1999, 1:327-333.

53. Binder M, Larsson K-H, Matheny B, Hibbett DS: New orders of Agaricomycetidae Amylocorticiales ord. nov. and Jaapiales ord. nov.: Early diverging clades of Agaricomycetidae were dominated by corticoid forms. Mycologia 2010, 102:865-880.

54. Murray MG, Thompson WF: Rapid isolation of high molecular weight plant DNA. Nucleic Acids Research 1980, 8:4321-4325.

55. Gardes M, Bruns TD: ITS primers with enhanced specificity for basidiomycetes-application to the identification of mycorrhizae and rusts. Molecular Ecology 1993, 2:113-118.

56. Vilgalys $\mathrm{R}$, Hester M: Rapid genetic identification and mapping of enzymatically amplified ribosomal DNA from several Cryptococcus species. Journal of Bacteriology 1990, 172:4238-4246.

57. Hibbett DS: Phylogenetic evidence for horizontal transmission of group I introns in the nuclear ribosomal DNA of mushroom-forming fungi. Molecular Biology and Evolution 1996, 13:903-917.

58. White TJ, Bruns T, Taylor JW: Amplification and direct sequencing of fungal ribosomal RNA genes for phylogenetics. In PCR Protocols: a guide to methods and applications. Edited by: Innis MA, Gelfand DH, Sninsky JJ, White TJ. San Diego, California: Academic Press; 1990:315-321.

59. Matheny P, Wang Z, Binder M, Curtis J, Lim Y, Nilsson R, Hughes K, Hofstetter V, Ammirati J, Schoch C, Langer E, Langer G, McLaughlin DJ, Wilson AW, Frøslev T, Ge Z-W, Kerrigan RW, Slot JC, Yang Z-L, Baroni TJ, Fischer M, Hosaka K, Matsuura K, Seidl T, Vauras J, Hibbett DS: Contributions of $r p b 2$ and tef1 to the phylogeny of mushrooms and allies (Basidiomycota, Fungi). Molecular Phylogenetics and Evolution 2007, 43:430-451.

60. Kauserud H, Schumacher T: Outcrossing or inbreeding: DNA markers provide evidence for type of reproductive mode in Phellinus nigrolimitatus (Basidiomycota). Mycological Research 2001, 105:676-683.

61. Hall TA: BioEdit: a user-friendly biological sequence alignment editor and analysis program for Windows 95/98/NT. Nucleic acids symposium series 1999, 41:95-98.

62. Goloboff PA, Farris JS, Nixon KC: TNT, a free program for phylogenetic analysis. Cladistics-the International Journal of the Willi Hennig Society 2008 24:774-786.

63. Farris JS: The future of phylogeny reconstruction. Zoologica Scripta 1997, 26:303-311.

64. Nylander JAA: MrModeltest 2.3. Program distributed by the author. Evolutionary Biology Centre, Uppsala University; 2004

65. Huelsenbeck JP, Ronquist F: MRBAYES: Bayesian inference of phylogenetic trees. Bioinformatics 2001, 17:754-755.

66. Ronquist F, Huelsenbeck JP: MRBAYES 3: Bayesian phylogenetic inference under mixed models. Bioinformatics 2003, 19:1572-1574.

67. Drummond A, Ho S, Phillips M, Rambaut A: Relaxed phylogenetics and dating with confidence. PLoS Biology 2006, 4:e88.

68. Ryberg M, Matheny PB: Dealing with incomplete taxon sampling and diversification of a large clade of mushroom-forming fungi. Evolution 2011.

69. Smith SY, Currah RS, Stockey RA: Cretaceous and Eocene poroid hymenophores from Vancouver Island, British Columbia. Mycologia 2004, 96:180-186.

70. Hibbett DS, Grimaldi D, Donoghue MJ: Cretaceous mushrooms in amber. Nature 1995, 377-487.

71. Hibbett DS, Grimaldi D, Donoghue MJ: Fossil mushrooms from Miocene and Creaceous amber and the evolution of homobasidiomycetes. Amercian Journal of Botany 1997, 84:981-991.

72. LePage BA: The evolution, biogeography and palaeoecology of the Pinaceae based on fossil and extant representatives. ISHS Acta Horticulturae 2003, 615:29-52.
73. Ronquist F: Dispersal-vicariance analysis: A new approach to the quantification of historical biogeography. Systematic Biology 1997, 46:195-203.

74. $Y u Y$, Harris AJ, He X: RASP (Reconstruct Ancestal State in Phylogenies).

75. Ree RH, Moore BR, Webb CO, Donoghue MJ: A likelihood framework for inferring the evolution of geographic range on phylogenetic trees. Evolution 2005, 59:2299-2311

76. Olsson U, Alström P, Gelang M, Ericson PGP, Sundberg P: Phylogeography of Indonesian and Sino-Himalayan region bush warblers (Cettia, Aves). Molecular Phylogenetics and Evolution 2006, 41:556-565.

77. Sanmartin I, Van Der Mark P, Ronquist F: Inferring dispersal: a bayesian approach to phyleogeny-based island biogeography, with special reference to the Canary Islands. Journal of Biogeography 2008, 35:428-449.

78. Donk MA: Notes on Malesian Fungi 1. Bulletin of the Botanic Gardens Buitenzorg 1948, 3:473-482.

79. Won H, Renner SS: Dating dispersal and radiation in the Gymnosperm Gnetum (Gnetales)-clock calibration when outgroup relationships are uncertain. Systematic Biology 2006, 55:610-622.

80. Crisp MD, West JG, Linder HP: Biogeography of the terrestrial flora., 2 1999, 1.

81. Upchurch P: Gondwanan break-up: legacies of a lost world? Trends in Ecology \& Evolution 2008, 23:229-236.

82. McLoughlin S: The breakup history of Gondwana and its impact on preCenozoic floristic provincialism. Australian Journal of Botany 2001, 49:271-300.

83. Sanmartín I, Ronquist F: Southern Hemisphere biogeography inferred by event-based models: Plant versus animal patterns. Systematic Biology 2004, 53:216-243

84. Hugall AF, Lee MSY: The likelihood node densitiy effect and consequences for evolutionary studies of molecular rates. Evolution 2007, 61:2293-2307.

85. Cook LG, Crisp MD: Not so ancient: the extant crown group of Nothofagus represents a post-Gondwanan radiation. Proceedings of the Royal Society B: Biological Sciences 2005, 272:2535-2544.

86. Peterson KR, Pfister DH, Bell CD: Cophylogeny and biogeography of the fungal parasite Cyttaria and its host Nothofagus, southern beech. Mycologia 2010, 102:1417-1425.

87. Lomolino MV, Riddle BR, Brown JH: Biogeography. Sunderland, Massachusetts: Sinauer Associates; 32005.

88. Takamatsu S, Matsuda S, Niinomi S, Havrylenko M: Molecular phylogeny supports a northern hemisphere origin of Golouinomyces (Ascomycota: Erysiphales). Mycological Research 2006, 110:1093-1101.

89. Sanmartín I, Enghoff H, Ronquist F: Patterns of animal dispersal, vicariance and diversification in the Holartic. Biological Journal of the Linnean Society 2001, 73:345-390.

90. Lydolph MC, Jacobsen J, Arctander P, Gilbert MTP, Gilichinsky DA, Hansen AJ, Willerslev $E$, Lange L: Beringian paleoecology inferred from permafrost-preserved fungal DNA. Applied and Environmental Microbiology 2005, 71:1012-1017.

91. Geml J, Laursen GA, O'Neill K, Nusbaum HC, Taylor DL: Beringian origins and cryptic speciation events in the fly agaric. Molecular Ecology 2006, 15:225-239.

92. Chapela IH, Garbelotto M: Phylogeography and evolution in matsutake and close allies inferred by analyses of ITS sequences and AFLPs. Mycologia 2004, 96:730-741.

93. Eastwood D, Floudas D, Binder M, Majcherczyk A, Schneider P, Aerts A, Asiegbu FO, Baker SE, Barry K, Bendiksby M, Blumentritt M, Coutinho PM, Cullen D, de Vries RP, Gathman A, Goodell B, Henrissat B, Ihmark K, Kauserud H, Kohler A, LaButti K, Lapidus JL, Lee Y-H, Lindquist E, Lilly W, Lucas S, Morin E, Murat C, Oguiza JA, Park J, et al: The plant cell wall decomposing machinery underlies the functional diversity of forest fungi. Science 2011.

94. LePage B, Currah R, Stockey R, Rothwell G: Fossil ectomycorrhizae from the Middle Eocene. American Journal of Botany 1997, 84:410-412.

doi:10.1186/1471-2148-11-230

Cite this article as: Skrede et al:: Evolutionary history of Serpulaceae (Basidiomycota): molecular phylogeny, historical biogeography and evidence for a single transition of nutritional mode. BMC Evolutionary Biology 2011 11:230. 